\title{
THE IMPACT OF VIDEO GAMES ON STUDENT GPA, STUDY HABITS, AND TIME MANAGEMENT SKILLS: WHAT'S THE BIG DEAL?
}

\author{
Jordan Weaver,Walsh University,jordanweaver@walsh.edu \\ Philip Kim,Walsh University,pkim@walsh.edu \\ Richard L. Metzer, Robert Morris University, rlmst26@mail.rmu.edu \\ Julie M. Szendrey, Walsh University, jszendrey@walsh.edu
}

\begin{abstract}
Playing video games has become one of the largest leisure activities in the world. This study examines the effects video games have on college students, their grade point averages, time management, and study habits. Existing literature has linked video game usage as being negatively correlated with each of these three variables. This research, using a sample of the undergraduate student population at a private university in northeast Ohio, found a statistically significant correlation between video game usage and grade point average. Statistically significant relationships were not found between video game usage and the variables of time management skills or study habits. It is important that college students are aware of these possible negative effects of video game usage on their academic performance. This research can serve as a foundation for future research on the impact of video game playing and student performance.
\end{abstract}

Keywords: Videogames, GPA, Study Habits, Time Management Skills, Student Performance

\section{INTRODUCTION}

The video game industry has flourished to become the world's largest entertainment medium [14]. The industry posted an estimated $\$ 34.2$ billion in revenue in 2012 , and revenue is expected to grow at an average of $5.5 \%$ over the next five years [8]. The advancements in technology have led to video games that are increasingly complex, immersive, engaging, and enabling of a wide range of activities, goals, and social behavior [14]. It is now difficult to find a household in the United States that does not have some sort of video game system, whether it is from common video game consoles or pc-based computer games. Due to the engaging nature of video games, users often find them to be a common part of their normal leisure activities, and spend considerable amounts of time playing them. U.S. gamers are now playing video games an average of 8 hours a week and this number is steadily rising [17].

\section{Purpose Statement}

The primary purpose of this research is to explore the correlation of video games with college-age student grade point average (GPA). Additionally, it aims to discover the relationship between video games, time management skills, and study habits. Existing research $[1,3,5,7,10,11,15 \& 16]$ attempts to look into the relationship between video game usage and school performance, but the majority of research focuses on adolescents under the age of 18 , primarily elementary-age students. This research will focus on measuring the impact of video game usage and college students' performance in the classroom, study habits and the time management skills.

\section{Target Demographic}

College-age students are the primary target demographic of this research. They are a group that needs to be studied when discussing video games because they constitute large demographic of video game users. This comes in large part because the majority of students are independent and out from under parental supervision for the first time [1,4]. Video games can be played in part to reduce stress that comes with college and its requirements. They are also sometimes used to shirk the responsibilities of studying for exams and other coursework. And yet, studying for courses, passing exams, and completing assignments are necessary for degree completion. A report by the Organization for Economic Co-operation and Development [13] states that "the job market in the U.S. is particularly difficult for those without a college degree" (p. 5). It is important that students that attend college make the most out of their time in school, acquire a useful skill set, and graduate with knowledge and proficiency in their chosen major that will help 


\section{Issues in Information Systems \\ Volume 14, Issue 1, pp.122-128, 2013}

them become gainfully employed. A recent study states that the U.S. is "the only country where attainment levels among those just entering the labor market (25-34 year olds) do not exceed those about to leave the labor market (55-64 year olds)" [13, p. 2]. A report by the National Center for Educational Statistics states that the graduation rate of full-time, first-time students attending a four year institution is only $57 \%$ [9]. Gerdes and Millinckrodt [6] state that the contributing factors to this number include academic adjustment, social adjustment, and personal or emotional adjustment. There are multiple factors that can effect on the academic success of a college student.

Two other factors that go hand in hand with academic success in college are time management skills and study habits. College is the first time in many students' lives when they can determine what schedule they will follow. Some students struggle with that responsibility, and have trouble allotting enough time towards academic activities such as studying. Britton and Tesser [2] point out that educational achievement, like intellectual achievement, takes time, and is affected by time management practices. Course work at the University level and specifically as the student progresses through his/r major requires time management skills and good study habits to ensure success. Britton and Tesser [2] explain that " $67 \%$ of students at a particular university report that their greatest personal need (of 40 needs on a checklist) was to "manage my time more effectively"' (p. 406). College students have a limited amount of time to allocate to academics, and unfortunately Ogletree and Drake [12] explain that an increase of time spent on a leisure activity, such as video games could result in problematic consequences in other areas. Students that have good time management skills are more confident and less stressed with the day to day tasks that come about. Grades depend on the quality of work that is done, and the quality of performance is affected by time management; therefore, "grade point average would be expected to be influenced by time-management skills" [2, p. 406]. Time management affects how much a student studies, as well as how much stress the individual is subjected to. Gerdes and Mallinckrodt [6] state that "time management, study skills, anxiety management, and an appropriate course load may also be helpful for building confidence, and, ultimately, academic success" (p. 287). Time management and study habits affect many aspects of a student's life, and are essential to maintaining a higher grade point average and achieving academic success in college.

\section{Research Questions}

This research aims to find out, how does video game usage impact time management, study habits, and GPA? The purpose of this study is to observe and determine the extent to which the independent variable (video game usage) correlates to changes in the dependent variables (GPA, study habits, and time management).

The study will be designed to test the following hypotheses:

H1: Those students who report higher video game usage will have lower GPA's.

H2: Higher video game usage will negatively impact students' study habits.

H3: Higher video game usage will negatively impact the students' time management skills.

\section{METHODOLOGY}

This study employed a non-experimental and correlational research design. This quantitative study involved the primary investigator observing and describing a current condition and behavior (video game usage, GPA, study habits, time management skills). The researchers utilized a modified survey to describe attitudes, beliefs, and behaviors of the college-age population. Descriptive correlational research was chosen for this study because quantitative survey data was going to be collected with the intent of analyzing the degree of the relationship among the variables.

Prior to conducting the actual study, one pilot study focus group was conducted to determine the clarity, usefulness, and effectiveness of the of the survey instrument. The draft survey questionnaire was presented to five individuals, and they gave feedback pertaining to things such as, the ease to which the questions were understood, as well as the overall structure of the survey and if it worked well to get the types of responses desired. These individuals were all members of the target demographic of current students at the 


\section{Issues in Information Systems \\ Volume 14, Issue 1, pp.122-128, 2013}

primary investigator's institution. Using the suggestions and feedback, appropriate changes were made to the survey.

The age range of the included subjects in the sample population ranged anywhere from 18-35, with the mean age of respondents being 20.9 years. To be eligible to participate in the study, the subjects were required to be current university students. The target institution is a small private university located in northeast Ohio, consisting of slightly fewer than 3000 students, made up of both undergraduate and graduate students. The sample size was 193 respondents.

In this research study, the independent variable was the amount of video game usage, measured in hours played by the survey population. On the survey instrument, the initial descriptive demographic questions were followed up with a yes or no question asking if the subject played video games. An answer of "yes" moved them on to continue the rest of the survey, while a "no" answer ended the survey for the subject, as all the following questions were video game related. There were two other specific questions in the survey that measured the amount of video game usage: one asked the average hours of video games played during the week (Monday through Friday), and the average hours of video games played on the weekend (Saturday and Sunday). For the purposes of analysis, the two hour totals were combined into one value of average hours of video games played per week. This total had a mean video game hours played per week of 13.38 hours. The mean video game usage (13.38 hours) of the population was used as a cutoff point, and every user that reported a usage less than this mean was coded " 0 ", and categorized as a low usage video game user. Every user that reported a usage of higher than the population mean was coded "1", and categorized as a high video game user. This was done to simplify and clarify the binomial analysis.

The dependent variables in the research study were the individual student's GPA, time management skills, and study habits. The purpose of the research was to see how changes in the independent variable of video game usage correlated to changes in the above listed dependent variables. There were several specific questions on the survey instrument that measured each dependent variable. The part of the survey that dealt with time management asked the subject two questions: how often the subject skipped class due to video games, and how often the subject lost sleep due to video games. These questions had a fine-point Likerttype response scale ranging from very rarely to very frequently. For analysis purposes, once the data was collected, these responses were coded from 1-5, with 1 being very rarely and 5 being very frequently. For study habits, the survey asked the subject: on average how long they studied per week and how often the subject had trouble paying attention in class. The first question collected a numerical value of hours per week. The second question also had a five-point Likert-type response scale response ranging from very rarely to very frequently. For analysis purposes, once the data was collected, these responses were also coded from 1-5, with 1 being very rarely and 5 being very frequently. To measure GPA, the survey asked the subjects to give their high school GPA, college GPA, and a response to whether or not they felt video games had a negative effect on their grades. Once the data was collected, it was determined that the high school GPA was unneeded, so that information was not used. College GPA was the more relevant figure which was reported using a scale of 0.0-4.0. The final question asked whether or not subjects felt that video games had a negative effect on their school grades, with responses ranging from strongly disagree to strongly agree. For analysis purposes, once the data was collected, these responses were also coded from 15 , with 1 being strongly disagree, and 5 being strongly agree.

\section{RESULTS}

The independent variable of video game usage was measured as average hours played in a common week. The video game usage for the study population ranged from a low of one hour to a high of 60 hours per week. The mean hours played was equal to 13.38 hours while the mode response was six hours per week.

\begin{tabular}{|l|c|c|c|}
\hline \multicolumn{4}{|c|}{ Usage Category } \\
& High & Low & Total \\
\hline Users & 50 & 93 & 143 \\
\hline Video game usage & $>13.38$ hours & $<13.38$ hours & \\
\hline
\end{tabular}




\section{Issues in Information Systems \\ Volume 14, Issue 1, pp.122-128, 2013}

The users that reported below 13.38 hours were coded as a " 0 ", or low usage video game players, and all of the users that reported above 13.38 hours were coded as a "1", or high usage video game players. The users were split into these two different categories, resulting in 93 users that qualified as low usage video game players, and 50 users that qualified as high usage video game players.

The dependent variables evaluated in the survey questions were the students' GPA, time management skills, and study habits. The mean GPA of the survey population was 3.34 out of a 4.0 scale, with a mode of 3.0. Respondents to the question asking if subjects felt that video games had a negative effect on their grades reported a mean response, on a coded scale of 1-5 of 1.71, with the mode response being a 1. For time management, the mean response to how often the subject skipped class due to video games on the coded scale of 1-5 was a 1.13, with the mode response being 1 . The mean response to how often the subject lost sleep due to video games on the coded scale of 1-5 was a 2.06, with the mode response still being 1 . When looking at the study habits of the subjects, the question of how long the students studied per week and how often the student had trouble paying attention in class were used. For the average hours studied per week, the average response of 11.84 hours, with a mode response of 10 hours. The mean response to how often the subject had trouble paying attention in class on the coded scale of 1-5 was 2.39 , with the mode response being 2 .

To test for correlation between the amount of video game usage and the dependent variables, $t$-tests were used. As previously stated, there were 93 users in the low usage video game player category and 50 users in the high usage video game category. The $t$-tests looked at the mean responses to each question to see if there was a statistically significant difference between the mean of the low usage players and the high usage players. The relevant differences in means, along with $t$-test numbers, $p$-values, are shown in figure 2 .

\begin{tabular}{|l|c|c|c|c|c|}
\hline \multirow{2}{*}{$\begin{array}{l}\text { Low Usage } \\
\text { (Mean) }\end{array} \quad \begin{array}{c}\text { Usage } \\
\text { (Mean) }\end{array}$ T-test p-value Sig. } \\
\hline Current college GPA & 3.41 & 3.22 & 2.04 & 0.043 & $* *$ \\
\hline Grades Negatively Impacted & 1.61 & 1.88 & -1.67 & 0.097 & $*$ \\
\hline Skipping Class & 1.11 & 1.16 & -0.61 & 0.541 & \\
\hline Lose Sleep & 1.82 & 2.50 & -3.82 & 0.000 & $* *$ \\
\hline Trouble Paying Attention in Class & 2.28 & 2.60 & -1.70 & 0.091 & $*$ \\
\hline Hours Spent Studying in a Week & 10.97 & 13.46 & -1.30 & 0.196 & \\
\hline
\end{tabular}

Figure 2

From this table, the differences between the two categories of low usage video game players and high usage video game players are noted. The low usage video game player category reported a mean college GPA of 3.41, and the high usage video game player category reported a mean college GPA of 3.22. The $t$ test results in a value of 2.04 and returns $a p$-value of.043, noting there is a statistically significant between the two groups: low and high video game users and overall GPA.

When evaluating the impact of video games on grades, the low usage video game players reported a mean response of 1.61, and the high usage video game players reported a mean response of 1.88, on the coded scale of $1-5$. The $t$-test results in a value of -1.67 and returns a $p$-value of .097 , while not statistically significant at the .05 level. While not statistically significant in a difference of means, the results suggest that students believe that high video game usage will have a negative impact on grades. 


\section{Issues in Information Systems \\ Volume 14, Issue 1, pp.122-128, 2013}

When evaluating how often the subjects skipped class because of video games, the low usage video game players reported a mean response of 1.11, and the high usage video game players reported a mean response of 1.16 , on the coded scale of 1-5. The $t$-test returned a value of -0.61 with a $p$-value of 0.541 . While there was no statistically significant difference between the two groups, these responses are telling as both low and high video game user groups feel strongly that any video game usage can contribute to skipping or missing class.

For the responses to time management, the respondents were asked to determine whether video game usage caused the students to lose sleep. Low usage video game players reported a mean response of 1.82, and high usage video game players reported a mean response of 2.50, on the coded scale of 1-5. The $t$-test returned a value of -3.82 and a $p$-value of 0.00 . There is a statistically significant difference between the two groups. Low video game users reported a stronger likelihood of loss of sleep due to video game usage. Which is an interesting result, as one would expect the higher video game usage group to report loss of sleep due to video games.

When evaluating the question asking subjects had trouble paying attention in class, the low usage video game players reported a mean response of 2.28, and the high usage video game players reported a mean response of 2.60, on the coded scale of 1-5. The $t$-test value was -1.70 , and the corresponding $p$-value was 0.091. Both low and high user groups did not feel as strongly that video game usage effected their ability to pay attention in class.

Finally, when evaluating how many hours the subjects spent studying per week, the low usage video game players reported a mean response of 10.97 hours, and the high usage video game players reported a mean response of 13.46. The $t$-test value was -1.30 , and the corresponding $p$-value was .196 .

\section{DISCUSSION}

The results showed that students reporting a high category usage of video games did report lower GPA's than students reporting a low category usage of video games. This data agrees with previously conducted and cited research such as Anand [1], Harris \& Williams [7], and Stinebrickner \& Stinebrickner [16]. Research by Anand [1] also found the correlation between higher video game usage and lower GPA to be significant on a $95 \%$ confidence interval, which is comparable to the results of this study. Harris \& Williams [7] also determined a significant decrease in GPA as video game usage went up. The results of Stinebrickner \& Stinebrickner [16] were similar to this study in that increased video game usage resulted in a drop in GPA of 0.241 on a 4.0 scale, while this research determined a drop in GPA of 0.19 . These were both significant drops in GPA. This research supports previous research conducted and points to the fact that higher video game usage does indeed have a negative correlation with students' GPA.

When observing the study habit questions, subjects were asked if they had trouble paying attention in class and how many hours a week they studied. For the trouble paying attention in class question, the $t$-test done on the difference in means between the two categories resulted in a $t$-test value of -1.71 and a $p$-value of .091. There was a difference in means, but not at the statistically significant $p$-value of $<.05$. For the amount of hours studied question, the high usage category reported higher study hours per week than the low usage category. High users reported a mean of 13.46 hours per week and low users reported a mean of 10.97 hours per week. However, the $t$-test returned a value of -1.30 and a $p$-value of 0.196 , so this difference was not found to be statistically significant. Previous research as Britton and Tesser [2] state that "researchers generally agree that intellectual achievement takes time and perseverance" (p. 405). The results showed, however, that high usage video game players actually studied almost three hours more than the low usage video game players. This result was not anticipated. One of the reasons for this result could be the fact that high usage video game players actually need more study time to comprehend their school work. They are spending a large amount of time playing video games, and they may feel as if they need to catch up, so they try to compensate by studying more. This logic could also support the question asking subjects if they have trouble paying attention in class. There was a difference in mean responses, as high usage video game players reported that they had more trouble paying attention in class when compared with low usage video game players. This difference in means, however, was not shown to be statistically significant. This is in contrast to the research done by Stinebrickner \& Stinebrickner [16] which stated that 


\section{Issues in Information Systems \\ Volume 14, Issue 1, pp.122-128, 2013}

first-year college students with a video game console studied forty minutes less a day on average than students without a video game console. It does, however, somewhat agree with the conclusion by Harris \& Williams [7], in which they could not conclude that study habits were correlated with video game usage.

When looking at the time management questions, the subjects were asked if they skipped class because of video games, and if they ever lost sleep from video games. For the skipping class question, the difference in means between the two categories resulted in a $t$-test value of -0.61 and a $p$-value of .541. This shows that the difference in means is not one of significance. However, when asked about loss of sleep, the $t$-test resulted in a $t$-test value of -3.82 and a $p$-value of less than 0.000 . This showed that high usage video game users were playing video games more, and this was causing them to play late hours that in turn caused them to lose sleep. Losing sleep can have a large impact on your academic life. Grades depend on the quality of work that is done, and time management affects the quality of performance. Britton \& Tesser [2] state that "grade point average would be expected to be influenced by time-management skills" (p.406), and Gerdes and Mallinckrodt [6] state the importance of time management skills when it comes to academic success. The fact that high usage video game players are losing sleep because of video games shows that these individuals are not managing their time appropriately enough to ensure that they get enough sleep. This could also be because video game players lose track of time when they are playing, which is supported by research done by Woods, Griffiths, \& Parke [19].

\section{CONCLUSIONS}

In conclusion, there was a distinct and significant difference in the reported GPA's between high usage video game players and low usage video game players. This is a very important finding as it relates to the college-age demographic that this research focused on. To reiterate previously cited research, Weaver [18] states that over $70 \%$ if college students report being avid video game players, due to the fact that they have limited parental supervision and flexible schedules. This research suggests that increased video game usage leads to lower GPA's in the college-age demographic.

This research set out to discover the relationship between video games, and their effect on time management skills, study habits, and student GPA. The results show that higher video game usage correlates to lower GPA. The research was inconclusive in proving that there was a relationship between video game usage and time management skills or study habits. Further research could possibly look further into these relationships.

\section{REFERENCES}

1. Anand, V. (2007). A study of time management: The correlation between video game usage and academic performance markers. CyberPsychology \& Behavior, 552-559.

2. Britton, B. K., \& Tesser, A. (1991). Effects of time-management practices on college grades. American Psychological Association, 83(3), 405-410.

3. Gentile, D. A. (2009). Pathological video-game use among youth ages 8 to 18. Psychological Science, 594-602.

4. Gentile, D. A., \& Walsh, D. A. (2002). A normative study of family media habits. Journal of Applied Developmental Psychology, 23, 157-178.

5. Gentile, D. A., Lynch, P. J., Linder, J. R., \& Walsh, D. A. (2004). The effects of violent video game habits on adolescent hostility, aggressive behaviors, and school performance. Academic Pres: Journal of Adolescence, 5-22.

6. Gerdes, H., \& Mallinckrodt, B. (1994). Emotional, social, and academic adjustment of college students: A longitudinal study of retention. Journal of Counseling \& Development, 72, 281-288.

7. Harris, M. B., \& Williams, R. (1985). Video games and school performance. Education, 105(3), 306-309.

8. Kaczanowska, A. (2012). Ibisworld: Video games in the US. Retrieved from http://clients.ibisworld.com/industryus/ataglance. aspx?indid=2003. 


\section{Issues in Information Systems \\ Volume 14, Issue 1, pp.122-128, 2013}

9. Knapp, L. G., Kelly-Reid, J. E., \& Ginder, S. A. U.S. Department of Education, National Center for Educational Statistics. (2010). Enrollment in postsecondary institutions, fall 2008; graduation rates, 2002 \& 2005 cohorts; and financial statistics, fiscal year 2008.

10. Messerly, J. G. (2004). How computer games affect cs (and other) students. Viewpoint, 29-31.

11. Moble, T., Kleimann, M., Rehbein, F., \& Pfeiffer, C. (2010). Media use and school achievement boys at risk?. British Journal of Developmental Psychology, (28), 699-725.

12. Ogletree, S. M., \& Drake, R. (2007). College students' video game participation and perceptions: Gender differences and implications. Sex Roles, 56(7), 537-542.

13. Organization for Economic Co-operation and Development. (2011). Country note-united states. In Education at a Glance 2011: OECD indicators (pp. 1-10). Paris, France: OECD Publishing.

14. Ryan, R. M., Rigby, C. S., \& Przybylski, A. (2006). The motivational pull of video games: A selfdetermination theory approach. Motivation and Emotion, 30(4), 347-363.

15. Skoric, M. M., Ching Teo, L. L., \& Neo, L. (2009). Children and video games: Addiction, engagement, and scholastic achievement. CyberPsychology \& Behavior, 567-572.

16. Stinebrickner, T. R., \& Stinebrickner, R. National Bureau of Economic Research, (2007). The casual effect of studying on academic performance (Working Paper 1334). Retrieved from website: http://www.nber.org/papers/w13341.

17. Takahashi, D. (2010, March 02). Gamesbeat: Time spent playing video games keeps going up. Retrieved from http://venturebeat.com/2010/03/02/time-spent-playing-video-games-keeps-goingup/.

18. Weaver, J. (2003, July 06). College students are avid gamers. Retrieved from http://www.msnbc.msn.com/id/3078424/ns/technology and science-games/t/college-students-areavid-gamers/.

19. Wood, R. T. A., Griffiths, M. D., \& Parke, A. (2007). Experiences of time loss among videogame players: an empirical study. CyberPsychology \& Behavior, 38-44. 